\title{
VULNERABILIDADES AGRAVADAS PELA PANDEMIA DE COVID-19 E A VEDAÇÃO AO RETROCESSO SOCIAL
}

\author{
Antônio José Xavier Oliveira ${ }^{1}$ \\ Luciana de Aboim Machado ${ }^{2}$
}

\begin{abstract}
Resumo:
Diante do atual contexto de pandemia e agravamento das vulnerabilidades; do processo inevitável de globalização; e da crise enfrentada pelo Estado Social, com a constante ameaça aos sistemas de proteção social dele derivados; o presente texto tem por objetivo destacar, partindo de uma análise histórico-descritiva e de uma abordagem lógico-dedutiva, o princípio da vedação ao retrocesso social como elemento de preservação da marcha evolutiva dos direitos sociais trabalhistas. O referido princípio apresenta-se como força de resistência e preservação das conquistas sociais alcançadas, sem deixar de garantir a segurança jurídica e preservar a democracia.
\end{abstract}

Palavras-chave: retrocesso social; pandemia; vulnerabilidade; globalização; COVID-19

\section{VULNERABILITIES AGGRAVATED BY THE COVID-19 PANDEMIC AND THE PROHIBITION OS SOCIAL REGRESSION}

\begin{abstract}
:
Faced with the current context of pandemic and worsening vulnerabilities, the inevitable process of globalization; and the crisis faced by the Social State with the constant threat to the social protection systems derived from it, this text aims to highlight, starting from a historicaldescriptive analysis and a logical-deductive approach, the principle of prohibition against social retrogression. as an element of preservation of the evolutionary march of labor social rights. This principle is presented as a strength of resistance and preservation of social achievements, while ensuring legal security and preserving democracy.
\end{abstract}

Keywords: social regression; pandemic; vulnerability; Globalization; COVID-19

\section{INTRODUÇÃO}

\footnotetext{
${ }^{1}$ Mestrando em Direito pela Universidade Federal de Sergipe. Especialista em Direito do Trabalho e Processo do Trabalho. Servidor Público do Tribunal de Justiça do Estado de Sergipe. E-mail: antoniojx@gmail.com

${ }^{2}$ Pós-Doutora em Direito Constitucional pela Universidade Federal da Bahia - UFBA e pela Università degli Studi G. d'Annunzio di Chieti-Pescara - UDA. Doutora em Direito do Trabalho pela Faculdade de Direito da Universidade de São Paulo-USP. Mestre em Direito do Trabalho, especialista em Direito do Trabalho e em Direito Processual Civil, todos pela Pontifícia Universidade Católica de São Paulo (PUC/SP). Professora Associada e Coordenadora do Programa de Pós-Graduação em Direito da Universidade Federal de Sergipe UFS. Coordenadora da Rede de Direitos Humanos e Transnacionalidade. Vice-Presidente da Asociación Iberoamericana de Derecho de Trabajo y de la Seguridad Social "Guillermo Cabanellas". Membro do Conselho Fiscal do Instituto Italo-brasileiro de Direito do Trabalho. Consultora da Ergon Associates (London). E-mail: lucianags.adv@uol.com.br
} 
O crepúsculo da segunda década do século XXI trouxe um peculiar contexto de crise global. Dentre todos os cenários possíveis de emergência planetária, o mundo se depara com as consequências de uma pandemia ainda em curso.

O atual estágio da globalização e da evolução dos transportes e das comunicações, bem como a velocidade de propagação do agente causador da emergência em saúde, deixaram nações inteiras, governos, organizações e instituições nacionais e internacionais completamente expostos em suas evidentes incapacidades de lidarem com a proteção dos mais vulneráveis.

A pandemia evidenciou a existência de parcelas fragilizadas da população. Explicitou a já conhecida incapacidade estatal de regular todas as situações possíveis - sejam elas prováveis ou não. Além disso, trouxe à luz a incapacidade de um estado mínimo, ausente e pouco participativo, de promover a proteção básica e eficaz aos mais vulneráveis em momentos de crise.

Neste contexto específico, sem pretensão de esgotar a temática, e diante do constante ataque a direitos sociais laborais garantidos na ordem jurídica brasileira - sempre ameaçada por constantes reformas trabalhistas e ameaças de desregulamentação -, tem-se por escopo do presente trabalho analisar se, no bojo da atual crise sistêmica e sanitária, é possível identificar o agravamento das vulnerabilidades e, no encalço destas, promover o reforço ao principal postulado principiológico de defesa das proteções já implementadas na ordem jurídica e das garantias de uma vida digna ao trabalhador hipossuficiente.

Destacar o estágio de crise perene imposto ao Estado Social de Direito, entendendo os motivos e a força desconstrutiva que levaram à falência um modelo que visava, prioritariamente, a proteção da dignidade humana e a garantia de um mínimo existencial. Entender o atual contexto pandêmico e seus impactos no agravamento das vulnerabilidades. Encarar o princípio da vedação ao retrocesso social como força de resistência, mesmo nos momentos de crise global. Estas são as premissas desta breve reflexão, que visa sobrelevar a preservação das garantias de vida e condições de trabalho dignas, em detrimento das constantes tentativas de fragilização das proteções laborais.

\section{AS VULNERABILIDADES AGRAVADAS E A BUSCA POR UMA IGUALDADE SUBSTANCIAL}


Seguindo o monitoramento global da respeitada Johns Hopkins University \& Medicine ${ }^{3}$, em 15/04/2021, o planeta estava prestes a ultrapassar cento e quarenta milhões de infectados - com números diários de infecções sempre acima de quinhentas mil pessoas desde novembro/2020 -, com quase três milhões de óbitos confirmados.

E, embora já existam algumas vacinas em uso e aplicação ao redor do mundo, o contexto de pandemia se encontra longe de ser superado.

A atual pandemia também surpreende pela rapidez com que se espalhou pelo planeta e pela quantidade de países afetados, tendo atingido todo os continentes do planeta com um tsunami de casos confirmados e mortes subsequentes.

O Brasil, no atual contexto planetário, merece destaques negativos em várias frentes. Nação com o terceiro maior número de casos e segundo maior recorde de óbitos confirmados - com a indisfarçável impressão de que referidos números encontram-se subdimensionados pela falta de testagem ampla da população e pela subnotificação de casos e óbitos - encontrase ainda num ambiente político e jurídico de incertezas, onde em muitas das vezes a cientificidade é escanteada em nome do capital político daqueles que ocupam postos chaves da República.

O país, em meio a tais pressões, encontra-se num ambiente político contaminado pela polarização entre esquerda e direita, com a imprensa tradicional sendo confrontada por novos modelos de propagação de notícias e informações que, muitas das vezes, atuam sem o necessário embasamento científico, o que acaba por produzir um ambiente jurídico igualmente politizado e casuístico.

Em complemento, as diferentes esferas do federalismo brasileiro disputam o protagonismo do "resgate" a uma população em estado inflacionado de vulnerabilidade, com diversos candidatos a heróis, mas poucos gestores eficientes e praticamente nenhum diálogo no sentido de encontrar soluções definitivas e práticas para o confronto com a emergência sanitária. Um contexto político e jurídico de agravamento das vulnerabilidades sem a devida resposta do Estado.

Neste contexto pandêmico, a questão do alcance da igualdade substancial se mostra ainda mais urgente e necessária.

\footnotetext{
${ }^{3}$ Pesquisadores da mencionada instituição de ensino disponibilizam um painel interativo e com atualizações regulares para rastreio da disseminação mundial do SARS-CoV2. Disponível em: https://coronavirus.jhu.edu/map.html. Acesso em 15.abr. 2021.
} 
A ideia, hoje ultrapassada, de que todos os seres humanos são naturalmente iguais e devem ser tratados sem qualquer distinção foi, ainda que de forma tímida, um avanço humanitário no momento histórico em que concebida.

O Estado Liberal pré-moderno, cristalizado a partir dos séculos XVIII e XIX, e refletido em documentos constitucionais nascidos neste período, a exemplo da Constituição da França de 1791 e da Constituição Imperial do Brasil de 1824, trouxe a concepção de igualdade formal, onde todos os cidadãos são iguais perante a lei e, graças a esta igualdade, sujeitos dos mesmos direitos e deveres.

Esta concepção limitada de igualdade, ainda meramente formal, teve o mérito de estimular alguns avanços dignificantes, a exemplo dos movimentos abolicionistas que se espalharam pelas Américas no século XIX e do surgimento de nações democráticas ao redor do planeta. Tanto é assim que agora, em meados do século XXI, como consequência deste avanço, monarquias hereditárias tornaram-se exceções, embora o autoritarismo permaneça uma ameaça, e a existência de trabalhadores em regime de escravidão ou servidão, apesar de ainda constatável, tornou-se conduta condenável pela maioria das ordens jurídicas contemporâneas.

No que concerne aos limites do presente trabalho, pode-se dizer que existe um verdadeiro paralelismo entre vulnerabilidade e igualdade. A ideia de vulnerabilidade também pode ser entendida como um conceito em constante evolução, assim como a igualdade. $\mathrm{Na}$ verdade, pode-se dizer que um conceito substancial de igualdade não pode ser alcançado sem que sejam consideradas as diversas vulnerabilidades existentes no contexto multicultural de uma sociedade que insiste em não confrontar a desigualdade e a falta de acesso a serviços públicos essenciais por grande parte de sua população.

Não por acaso, a primeira das reconhecidas vulnerabilidades é aquela inerente a todo e qualquer ser humano. Uma condição universal que une a todas as pessoas na fragilidade física natural, na possibilidade do sofrer danos, de estar suscetível a prejuízos de ordem física e mental.

Esta vulnerabilidade ontológica, segundo RE (2019, p. 315), é uma condição derivada da fragilidade humana natural e da circunstância de que convivemos em permanente contato com outros seres humanos, capazes tanto de sofrer dano, como também de causá-lo. Existem, por assim dizer, vulnerabilidades e dependências inevitáveis, surgidas e agravadas pela própria condição humana. A infância e a velhice, as enfermidades - ressaltadas no atual 
contexto pandêmico -, a proteção à maternidade e o acesso ao trabalho das mulheres nesta condição, são apenas alguns dentre os diversos exemplos possíveis.

FEITO (2007, p. 16), ao mencionar as ideias de Barry Hoffmaster, destaca que a vulnerabilidade é um traço característico da humanidade ainda mais básico que a própria razão, visto que é possível encontrar seres humanos em estado de irracionalidade. Da mesma forma, nos extremos da vida, seja na infância ou na velhice, o ser humano pode não ter a capacidade de se reconhecer, mas a vulnerabilidade estará presente. Ainda que a racionalidade possa ser um signo distintivo da humanidade, é a vulnerabilidade que nos torna iguais num contexto ontológico e diferentes nos demais contextos da vida em sociedade.

Existem também vulnerabilidades decorrentes do contexto social e das relações de poder: a pobreza; a falta de acesso à educação e à saúde; a hipossuficiência do trabalhador em face do patrão; a vulnerabilidade do consumidor em confronto com grandes corporações e com os fornecedores de serviços e produtos de massa; as diversas formas de preconceito e discriminação - cultural, étnica, sexual, de gênero, regional, etc. - e seus impactos na concretização de objetivos de vida e realização de sonhos daqueles que são vitimados por ela; dentre outras. Cada um destes problemas está relacionado a vulnerabilidades específicas e contextuais.

Assim, pode-se dizer sem receios, entender vulnerabilidade é mais plausível do que, simplesmente, conceituá-la. Trata-se de entendimento que demanda contexto, multiplicidade de visões de mundo e uma análise sempre "relacional".

Entender as diferentes vulnerabilidades detectáveis na vida em sociedade é permitir a evolução, em paralelo, do conceito de igualdade substancial. Por conta disso, analisar vulnerabilidades impõe a observância das múltiplas relações sociais existentes e de suas consequências. Tratam-se de entendimentos relacionais, impossíveis de serem compreendidos fora do contexto social multifacetado e de inclusão.

(...) no desconoce las diferencias, sino que, al contrario, reconoce todas y las
valoriza como otros tantos rasgos de la identidad de las personas, sobre cuya
concreción y especificidad cada una funda su amor propio y el sentido de la propia
autonomía en las relaciones com los demás. La igualdad en los derechos
fundamentales resulta así configurada como el igual derecho de todos a la
afirmación y a la tutela de la propia identidad, en virtud del igual valor asociado a
todas las diferencias que hacen de cada persona un individuo diverso de todos los
otros y de cada individuo una persona como todas las demás. (FERRAJOLI, Luigi,
2002, p. 76)

Ocorre que a proteção das minorias - aqui entendidas não apenas no sentido numérico da palavra, mas na dimensão de proteção e acesso aos centros de decisão e de poder 
num estado democrático fragilizado como o atual - é um desafio em constante mutação. Se, no passado, reconhecer a simples igualdade formal foi um avanço humanitário, no atual contexto de globalização dos mercados e, conforme se delineou no início deste trabalho, de constante ameaça sanitária pandêmica, são necessárias ferramentas que objetivem proteger aqueles mais expostos às vicissitudes destes tempos incertos.

O termo minoria deve ser reservado àqueles grupos sociais que, independentemente
de sua amplitude quantitativa, encontram-se qualitativamente em uma situação de
inferioridade, seja por fatores sociais, técnicos ou econômicos. Esta é, aliás, a
acepção que também atribuem ao termo os estudiosos de outras ciências sociais,
referindo-se usualmente a minorias como grupos sujeitos à dominação de outros
grupos prevalentes. É comum incluir-se no conceito a impossibilidade ou
dificuldade no exercício da cidadania, a incapacidade de defender de forma eficaz os
próprios interesses e a submissão perante a autoridade, controle ou poder de outros.
Em síntese: a vulnerabilidade é o critério central para a definição e identificação das
minorias. (TEPEDINO, Gustavo; SCHREIBER, Anderson, 2002, p. 136)

Desde os primórdios, a concepção do princípio de igualdade jurídica está ligada, intimamente, à existência de um conteúdo mínimo jurídico comum a todas as pessoas (SILVA, 2011, p. 41). Com o passar do tempo, esse mínimo jurídico foi sendo ampliado para garantir a implementação de novos patamares de civilidade e respeito às diferenças, aproximando a igualdade meramente jurídica de uma igualdade substancial. Aspectos de liberdade - ir e vir, pensar, expressar, escolher a própria fé, possuir, dentre tantos outros -, bem como aspectos de sociabilidade - educação, trabalho digno, saúde, moradia, segurança social, etc. - passaram a integrar a necessária visão de igualdade jurídica diante das diferenças e, porque não dizer, das vulnerabilidades.

Para os fins propostos do presente trabalho, manter-se-á o foco na vulnerabilidade existente, e facilmente constatável, da figura do hipossuficiente na relação de trabalho, ameaçado não apenas pelo atual contexto de pandemia, mas pelo cenário globalizado e pelas constantes ameaças de desregulamentação e retirada de direitos na seara trabalhista. Esta retirada, pura e simples, das normas de ordem pública com conteúdo protetivo, garantidoras de um patamar mínimo dignificante caracterizaria relevante retrocesso social.

Ter-se-ia o retorno a um sistema privatista absoluto já superado, destaque-se, até pelo direito civil contratual, deixando de reconhecer a vulnerabilidade do trabalhador hipossuficiente em face do poder econômico dos empregadores.

Embora não seja o foco específico do presente trabalho uma análise legislativa em particular, merecem menção, neste ponto, considerando o contexto pandêmico, as iniciativas estatais brasileiras de resposta à emergência sanitária na seara trabalhista, tais como as 
Medidas Provisórias 927 e 936. Referidos diplomas normativos trouxeram em seu bojo a prevalência dos acordos individuais entre patrões e empregados sobre a negociação coletiva e as leis de ordem cogente aplicáveis à disciplina laboral. Tratam-se de exemplos nítidos de como o contexto pandêmico pode ser utilizado pelas forças detentoras do poder político para repassar os custos da pandemia às classes menos favorecidas da população.

\section{A GLOBALIZAÇÃO E AS AMEAÇAS À REDE DE PROTEÇÃO TRABALHISTA}

No decorrer do presente texto, a menção ao Estado Liberal não escapa à constatação de que, ainda que ele seja o detentor do mérito de gestar o primeiro passo - a igualdade formal - da longa caminhada evolutiva em direção à concretização do princípio da isonomia, são justamente as ideias liberalizantes e de "estado mínimo" que se apresentam como principais ameaças à rede de proteção trabalhista.

A rede de proteções que visa a garantia ao trabalho digno é fruto, em verdade, da ruptura com o Estado Liberal e do desenvolvimento de uma nova faceta do aparato estatal, voltada à garantia de patamares mínimos de proteção social.

A não-intervenção estatal e o abstencionismo de práticas regulatórias, próprios do Estado Liberal, acarretaram um cenário de desequilíbrio social caracterizado pela exploração da força de trabalho, pela formação de monopólios econômicos e por uma desigualdade social crescente.

A ideia de um estado mínimo, não interventor e garantidor de liberdade irrestrita aos indivíduos alimentava a exploração das camadas mais pobres da população por uma burguesia que havia tomado para si o poder político após haver conquistado o poder econômico. Contudo, a estrutura estatal do Liberalismo não resistiu à sequência de abalos institucionais que marcaram o início do século XX. A partir de então, despontou um novo cenário, no qual se alterou o papel desempenhado pelo Estado em suas relações com os particulares (SAMPAIO, 2013, p. 66-67).

Existindo um vazio de proteção, a simples ideia de uma liberdade que, apenas formalmente, fazia a todos iguais já não era suficiente para aglutinar as diversas classes sociais e suas diferenças sob a égide de um Estado que se abstinha de participar e atuar como moderador ou regulador destas tensões socialmente estabelecidas. Como bem explica SUPIOT (2007, p. 270), a história social nos mostra que não basta proclamar a igualdade para 
que ela exista. A mera declaração da igualdade formal acaba por servir como instrumento de dominação, despojando os mais fracos das eventuais proteções que podem conquistar quando a ordem jurídica efetivamente reconhece as vulnerabilidades existentes.

O valor liberdade, sem embargo de sua importância, perdeu seu protagonismo, ocasionando uma mudança na estrutura do Estado Liberal, para se fazer substituir pela prevalente busca por uma igualdade substancial. Em verdade, almejava-se a presença de um aparato estatal que garantisse a proteção social e articulasse direitos e liberdades individuais com os direitos sociais garantidos por essa nova modalidade de atuação do Estado, incrementando, assim, o crescimento econômico e trazendo não apenas segurança jurídica, mas também segurança social.

Com a referida crise do Estado Liberal, surge o Estado Social de Direito (que, em algumas ordens jurídicas e econômicas mais desenvolvidas, atingiu o status de Welfare State, ou Estado de bem-estar social ${ }^{4}$ ), com a intervenção estatal nas ordens social e econômica, de modo a regular e balizar excessos, com o intuito de conferir proteção a direitos fundamentais de ordem e de alcance social. O Estado passou a agir nos mais variados campos da sociedade, dentre os quais a educação, a saúde, o trabalho humano e as relações contratuais formadas nas cercanias deste, a seguridade social e a assistência aos necessitados, apenas para citar alguns de seus mais relevantes exemplos.

Neste momento histórico, o Estado tornou-se o grande instrumento da ordem social no combate ao abuso do capital e à exploração do homem, bem como na prestação de serviços públicos aos mais necessitados (BARROSO, 2019, p. 83). É com a superação do Estado Liberal e com o surgimento de um novo patamar de proteções, que foram consagrados e identificados direitos sociais garantidores de um patamar existencial-material mínimo, visando a proteção do trabalhador e fruto das lutas e anseios da classe laboral em face da sociedade burguesa (CANOTILHO, 2003, 423-424). O Estado Social de Direito superou a proeminência do valor liberdade e erigiu os direitos de ordem social à dimensão estruturante da juridicidade e da própria democracia.

No Brasil, com especial ênfase na seara trabalhista, o surgimento deste novo patamar de direitos ocorreu em meio a uma tentativa da classe política dominante de capitalizar com

\footnotetext{
${ }^{4}$ O termo Welfare State pode ser encontrado na doutrina como sinônimo de Estado Social de Direito. Para fins de especificação, o presente trabalho trata Welfare State como o estágio final e bem sucedido do Estado Social de Direito em países que se apresentam como exceções na ordem jurídica e econômica mundial, tais como Dinamarca, Finlândia, Islândia, Noruega e Suécia.
} 
os avanços de referidas proteções em outras ordens jurídicas e, desta forma, incrementar o próprio capital político junto à classe trabalhadora - período que convencionamos chamar de "Era Vargas" -. Ainda assim, apesar da tendência histórica nacional de promover avanços humanitários com relevante atraso ${ }^{5}$, é impositivo reconhecer os efeitos dignificantes deste avanço no campo dos direitos sociais, garantidores de um patamar mínimo existencial (DELGADO, 2016, p. 61).

O Estado Social de Direito promoveu a regulamentação econômica e do mercado de trabalho, mudando a estrutura do Estado constitucional a partir da concretização de direitos de segurança social. Em verdade, foi capaz de concretizar direitos e proteções antes apenas formalmente previstos.

Na seara trabalhista, evoluiu-se a ponto de se reconhecer que a liberdade absoluta de contratação no espaço laboral merecia ser limitada, de forma a proteger a pessoa que não detinha, na relação, o poder e a capacidade econômica que conduziriam à exploração do ser humano vulnerável na busca pela simples subsistência.

Ocorre que esta estrutura de Estado, insuficientemente modulada, causou distorções graves, sendo a mais evidente delas a hipertrofia da função estatal executiva em comparação com os demais "poderes" constituídos. Segundo FERRAJOLI (2002, p. 64), este descompasso do Estado Social aconteceu, principalmente, pelo aumento dos espaços de discricionariedade dos aparatos burocráticos e não, simplesmente, por conta dos novos direitos e garantias previstos no ordenamento jurídico.

Os custos mal administrados desta empreitada em busca do bem-estar social causaram inchaço na máquina pública, abriram caminho para condutas administrativas nem sempre focadas no interesse público, expuseram problemas graves de gestão, causaram o desequilíbrio dos orçamentos nacionais e, com a internacionalização dos mercados a partir da década de 60 do século XX, provocaram desequilíbrios concorrenciais evidentes que estimularam a retomada de uma mentalidade de desregulamentação da economia e, por consequência, do mercado de trabalho e das proteções sociais que caracterizavam este modelo estatal $^{6}$.

\footnotetext{
${ }^{5}$ A extinção - formal - da escravidão e o estabelecimento de um regime democrático são os exemplos mais evidentes do delay histórico-evolutivo que parece caracterizar o Brasil.

${ }^{6}$ A essa retomada de conceitos próprios do Estado Liberal, modulada pelas exigências do globalismo comercial e cultural da segunda metade do século XX, convencionou-se chamar de neoliberalismo.
} 
Diante da aparente ausência de solução definitiva para a parcela da população assistida por programas sociais $^{7}$, o neoliberalismo e a globalização dos mercados internacionais passaram a impor uma reformulação na postura estatal, buscando afastar o ideal de uma sociedade voltada para a igualdade substancial e para proteção de um mínimo existencial garantidor de cidadania plena e coletiva.

The crisis of the welfare state thus translates into a crisis of democracy. During this crisis, European social sciences and law began to look to the US debate on vulnerability. The risk is then that this paradigm will be used not to renew the constitutional state in a feminist and post-identity direction, but rather to contribute to its erosion. This risk is especially evident when vulnerability is referenced in order to designate the "vulnerable groups" deserving protection, as if protecting such groups was a "moral duty" of the state. Such rhetoric expresses a paternalistic and stigmatising logic, which, moreover, can give rise to a form of socially constructed "vulnerability" (what Catriona Mackenzie, Wendy Rogers and Susan Dodds (2014, p. 1-29) have defined as "pathogenic vulnerability"). Furthermore, such a rhetoric of "vulnerability" often aims to suppress, or overshadow, references to social rights. (RE, 2019, p. 320).

Como bem registrou CANOTILHO (2015, p. 13) em sua análise acerca da crise do Estado Social, o definhar deste modelo de aparato estatal garantidor é, com efeito, o triunfo do globalismo neoliberal.

Apesar de considerada vencida pela passagem da História e pelo surgimento de uma "nova" força liberal articulada com a globalização dos mercados, a concepção de um Estado Social capaz de resguardar a cidadania, as proteções sociais e a dignidade da força de trabalho, em face das exigências - nem sempre justas - do capital permeou a elaboração da Constituição Federal de 1988, que elenca diversos dispositivos voltados ao tema da justiça social e da cidadania plena, merecendo destaque especial as disposições dos artigos $6^{\circ}, 7^{\circ}, 170$ e 193, mais óbvios exemplos no texto de uma Carta Política batizada de "cidadã" por conta desta orientação dignificante.

Os artigos mencionados acima, sem embargo de outros com igual orientação, tratam de disposições constitucionais relacionadas à justiça social e à cidadania, com especial foco no mundo das relações laborais. São verdadeiros comandos jurídicos dotados de eficácia e supremacia constitucional, que geram para o Estado brasileiro deveres de fazer e de não-fazer, não se tratando de meras exortações ou conselhos de valor puramente moral (MELLO, 2009,

\footnotetext{
${ }^{7}$ Um dos argumentos para a crítica neoliberal à atuação do Estado na proteção social dos mais necessitados é a possível criação de uma parcela de cidadãos propositalmente dependentes do aparato estatal. Ressalte-se que a existência de programas sociais sem contrapartida educacional ou estímulo à qualificação profissional e à reinserção no mercado de trabalho acabou reforçando esta argumentação.
} 
p. 55). Também garantem, numa relação jurídica naturalmente desbalanceada como a trabalhista, o reconhecimento da necessária proteção ao trabalhador.

Aos perigos da globalização e da concorrência desleal para com os menos favorecidos, soma-se, agora, a ameaça do contexto pandêmico. Inobstante o que seja apregoado pelo neoliberalismo ou pelas eventuais alternâncias entre esquerda e direita no comando do campo político nacional, é momento de se preservar as conquistas já adquiridas em busca da igualdade substancial e da cidadania plena. É hora de preservar a marcha progressiva dos direitos sociais trabalhistas.

\section{O PRINCÍPIO DA VEDAÇÃO AO RETROCESSO SOCIAL}

Compreendido o atual estágio de crise, seja do Estado Social, em virtude da globalização do mercados e do neoliberalismo, ameaçando os avanços já alcançados no tocante à busca pela igualdade substancial; seja do ambiente global, causando o agravamento das vulnerabilidades, considerado o atual contexto de pandemia; apresenta-se à análise - na concepção deste trabalho - a principal força de resistência, em matéria trabalhista, no tocante à preservação dos patamares de proteção laboral já consagrados.

Trata-se do princípio da vedação ao retrocesso social - nomenclatura mais utilizada na doutrina, onde também emerge como "princípio da proibição do retrocesso social", "proibição de contrarrevolução social" e "proibição da evolução reacionária" (CANOTILHO, 2003, p. 336-338) - que teve sua concepção na Alemanha, na década de 1970.

Diante da forte crise econômica e fiscal enfrentada por referido país, supostamente, ocasionada pelo Estado Social e suas crescentes demandas e atribuições, começou-se a discutir, ainda que de maneira embrionária, a ideia de que o desenvolvimento humano e social deveria ser protegido face às propostas de restrição de direitos e reformas no aparato estatal de bem-estar social, para, neste toar, ver garantida a sua marcha sempre progressiva.

A partir daí a ideia de vedação ao retrocesso social passou a reverberar em países como Suíça, França e Portugal, chegando, em seguida, ao Brasil.

No sistema constitucional brasileiro, trata-se de princípio implícito, derivado do mandamento fundamental da dignidade da pessoa humana (artigo $1^{\circ}$, III, CF), e extraído de diversas outras passagens da Carta Política, em especial, de seu preâmbulo, do $\S 1^{\circ}$ do artigo $5^{\circ}$ (considerando a máxima efetividade dos direitos fundamentais, bem como sua 
interpretação evolutiva), e do caput (parte final) do artigo $7^{\circ}$, guardando relação, ainda, com normas internacionais das quais o Brasil é signatário, tais como o Pacto de San Jose da Costa Rica (artigo 26) e o Pacto Internacional dos Direitos Econômicos, Sociais e Culturais da Convenção Americana de Direitos Humanos (artigo $2^{\circ}, \S^{\circ}$ ).

A discussão sobre a proibição ao retrocesso, no direito brasileiro, sobreleva-se ao refletimos sobre o alcance que o Estado Social de Direito atingiu em outras ordens jurídicas, notadamente as de países mais desenvolvidos economicamente, em comparação com a segurança social efetivamente implementada neste país com imensas desigualdades sociais e verdadeiros vácuos de proteção social.

Por óbvio, não há como equiparar o nível de proteção social de países subdesenvolvidos - onde ainda se almeja patamares ínfimos de resguardo à população, como a mera segurança alimentar - com o de nações mais desenvolvidas e com aparatos de proteção estatal mais amplos e eficientes.

No caso brasileiro, torna-se relevante e urgente a presente análise, diante da ameaça de desmantelamento do aparato de proteção social trabalhista que já se mostra insuficiente à garantia do mínimo existencial aos seus trabalhadores mais vulneráveis.

Apenas para mencionar alguns exemplos de iniciativas desregulamentadoras mais recentes no cenário jurídico nacional, sem a justificativa do contexto pandêmico, temos a reforma trabalhista de 2017 - lei 13.467/17 que, modificando disposições da Consolidação das Leis do Trabalho, trouxe restrições à caracterização dos grupos econômicos, à responsabilização dos sócios retirantes das empresas eventualmente acionadas no judiciário trabalhista, bem como a previsão de teletrabalho sem responsabilidade pelos custos inerentes à atividade laboral, além de vedar a ultratividade de normas coletivas negociadas - .

No contexto da atual pandemia, apresenta-se evidente as tentativas de permissão do ajuste individual entre empregado e empregador, sem a tutela sindical, sob a justificativa do estado de calamidade sanitária. A Medida Provisória 936/2020 - depois convertida na lei 14.020/2020 -, por exemplo, trouxe a previsão de redução de salários e de jornada mediante acordo individual entre o hipossuficiente e o tomador do serviço.

Mencionada vedação ao retrocesso social trata, nunca é demais reafirmar, de princípio de ordem constitucional, vinculado à concepção de segurança jurídica e à consagração da dignidade da pessoa humana. Verdadeiro mandado de otimização (ALEXY, 2011, p. 90-91), determina que sua concretização seja operacionalizada no mais alto grau 
possível das possibilidades jurídicas e das circunstâncias fáticas existentes, podendo funcionar, dentro do ordenamento jurídico constitucional, como agente limitador da produção de outras normas ou da interpretação possível de regras já existentes.

Não se pode falar em democracia sem que tenhamos segurança jurídica e, também, segurança social. É esta segurança - na ordem jurídica e na proteção por ela estabelecida que possibilitará aos indivíduos e à coletividade almejarem a realização de seus sonhos e a busca da felicidade. Trata-se de requisito inafastável na busca pela cidadania plena.

A própria ideia de segurança jurídica, garantida por diversos preceitos previstos no atual texto constitucional, servirá de alicerce para a consagração do princípio da vedação ao retrocesso como garantia de um mínimo existencial e segurança social dentro da democracia constitucional.

Sem pretensão de construir um conceito hermético, e diante do objetivo específico do presente texto, pertinente seguir as lições de DERBLI (2007, p. 296), que entendia o princípio da vedação ao retrocesso social como um limite à ação do legislador infraconstitucional já que, uma vez alcançado determinado patamar de concretização de uma norma constitucional de direito social, através de lei, seria defeso ao legislador suprimir ou reduzir essa concretização, sem que, ao menos, fosse criado mecanismo equivalente em substituição. A opção por uma conceituação simples e direta, mesmo diante da farta doutrina disponível, atende aos limites do presente estudo.

Trata-se de vetor principiológico - mandado de otimização, portanto, - cuja direção e sentido convergem para a segurança jurídica e para a dignidade da pessoa humana. Limita as ações legislativas desconstrutivas - vedando desregulamentações e limitando flexibilizações -, aprimorando a produção de normas jurídicas, ao tempo em que se visa promover a estabilidade da escalada em busca da cidadania plena, o progresso social, bem como a proteção ao mínimo existencial, sobretudo porque traz, em seus pressupostos, a ideia de "mecanismos compensatórios" - ou políticas substitutivas equivalentes (BARCELLOS, 2002, p. 69) -, capazes de permitir a evolução do ordenamento jurídico de proteção, sem que exista diminuição da rede de garantias e salvaguardas sociais.

Note-se que inexiste vedação completa à possibilidade de atuação do legislador. Há, apenas, uma proteção diante da possibilidade de retrocessão na garantia do núcleo essencial dos direitos sociais (SARLET, 2018, p. 454). 
O próprio conceito de mínimo existencial é dinâmico e pautado nas condições específicas de cada época. Trata, em síntese, da garantir a qualidade de vida e as condições sociais alicerçantes. Engloba direitos básicos, como educação, saúde, trabalho em condições dignas, assim como posições sociais e jurídicas que ultrapassem a necessidade de simples subsistência, como a proteção dos vulneráveis e o respeito à pluralidade. Neste sentido:

[...] sem o mínimo necessário à existência cessa a possibilidade de sobrevivência do
homem e desaparecem as condições iniciais da liberdade. A dignidade humana e as
condições materiais da existência não podem retroceder aquém de um mínimo, do
qual nem os prisioneiros, os doentes mentais e os indigentes podem ser privados.
(TORRES, 2001, p. 256).

Em conformidade com a ideia central deste texto, a concepção de mínimo existencial está vetorizada pelo compromisso de concretização da justiça social, numa relação direta entre o princípio da dignidade humana e o Estado Democrático de Direito.

Seguindo nas lições de SARLET (2018, p. 473), admite-se a ideia de que medidas supressivas ou restritivas, em matéria de direitos sociais, relacionadas ao mínimo existencial e sem previsão de mecanismos compensatórios eficazes, devem ser consideradas presumidamente inconstitucionais, especialmente quando afetam a dignidade da pessoa humana. Trata-se, por óbvio, de presunção apenas relativa, mas que reforça a garantia de proteção do mínimo existencial para o alcance de uma vida digna.

Ainda segundo SARLET (2018, p. 452-454), no âmbito do pensamento constitucional contemporâneo, um autêntico Estado de direito é também, primordialmente, um Estado de segurança jurídica. Assim, seria impossível chancelar a viabilidade da democracia acaso esta não buscasse, dentro de suas pretensões e sistemáticas próprias, a segurança jurídica e o império das leis.

Ocorre que a segurança jurídica constitui apenas uma das dimensões do princípio geral de segurança, que também inclui a segurança social - aqui reforçada pela noção já delimitada de patamares mínimos existenciais e de direitos sociais, em especial na seara trabalhista - e a própria segurança pessoal em face dos outros cidadãos e do Estado, decorrente dos direitos de liberdade próprios do Estado Liberal.

Assim, o princípio da vedação ao retrocesso social surge como expoente de um verdadeiro paralelismo. Enquanto o texto constitucional traz institutos específicos de segurança jurídica pessoal - ato jurídico perfeito, direito adquirido e coisa julgada (artigo $5^{\circ}$, XXXVI, Constituição Federal) saltam aos olhos como exemplos - o postulado da vedação ao 
retrocesso social é extraído do cerne constitucional para servir de garantia à segurança jurídica no plano social.

É, em suma, a resposta constitucional às eventuais ameaças aos patamares mínimos já concretizados de segurança social. Se a segurança jurídica pessoal pode ser traduzida nos institutos acima mencionados, a segurança social encontra seu escudo de defesa no postulado da vedação ao retrocesso social. A garantia aos patamares mínimos de proteção social e a salvaguarda dos direitos sociais que fazem parte deste núcleo constituem, portanto, imperativo de segurança jurídica e social próprios da democracia.

O princípio da vedação ao retrocesso social, entretanto, tem implicações e impactos efetivos e mais relevantes na atuação do legislador infraconstitucional.

Segundo GONÇALVES (2006, p. 236), cujas ideias são aqui apresentadas de maneira sintetizada, é possível alterar legislações, mas não as revogar simplesmente, sem que, no lugar das proteções extraídas, sejam previstas novas disposições legais ou programas de políticas públicas - no caso das proteções de ordem prestacional - que continuem a preservar as conquistas sociais já consagradas. É o legislador capaz de propor mudanças e avanços, não apenas retrocessos.

O sentido da proibição ao retrocesso social não é engessar o debate democrático ou os espaços de participação cidadã, em especial aquele reservado à produção legislativa, mas garantir, com segurança, condições materiais básicas para que a democracia não seja prerrogativa de poucos, refém de eventuais maiorias legislativas, ou vítima de contextos de crise como o atual período de pandemia, por exemplo.

Não se está paralisando ou anestesiando a atividade legislativa. Exigir-se-á criatividade na formulação de políticas substitutivas, instrumentos compensatórios ou, simplesmente, que o Estado finalmente consiga alcançar seus objetivos (artigo $3^{\circ}$, Constituição Federal) para que as políticas prestacionais e/ou de proteção social percam a necessidade de existir. Será necessário ouvir os diversos setores da sociedade, buscar alternativas e não, simplesmente, retirar direitos e proteções.

Apresenta-se, assim, a concepção de HÄBERLE (2003, p; 55) de que a Constituição se evidencia como processo público dialógico e de conflito, devendo as ações do Poder Público - aqui incluído o legislador infraconstitucional - integrarem referido diálogo, abrindo as portas para outros agentes sociais interpretarem e efetivarem as normas constitucionais 
(BRANCO, 2010). Neste sentido específico, possibilitando o alcance de alternativas à simples desregulamentação e retirada de direitos.

Trata-se, neste contexto, de efetivar os princípios fundamentais da cidadania e da dignidade da pessoa humana, apresentados no artigo $1^{\circ}$, II e III, da Constituição Federal fundamentos, também, do princípio da vedação ao retrocesso social.

Assim o princípio da vedação ao retrocesso social acaba por garantir uma atividade legislativa de maior qualidade e prospecção, evitando o já exacerbado desequilíbrio de forças existente (SOUTO MAIOR, 2000, p. 251) na luta diária daqueles que buscam justiça social em face dos que detém o poder político e econômico.

A análise acerca da exigência de contrapartidas - mecanismos compensatórios, políticas substitutivas, compensações legislativas, etc. -, em consagração ao postulado da proibição do retrocesso social, pode levar à conclusão de que uma determinada legislação, quando produzida sem a devida observância das necessidades sociais e de proteção aos mais necessitados, possui incompatibilidade normativa com todo o sistema constitucional e com o projeto de sociedade democrática que depende da eficácia dos direitos sociais (SOUTO MAIOR, 2000, p. 70-71). Caberá ao Judiciário, neste caso, agir de forma a evitar o retrocesso e a inconstitucionalidade dele decorrente.

Quando falo em "intervencionismo substancialista", refiro-me ao cumprimento dos
preceitos e princípios ínsitos aos Direitos Fundamentais Sociais e ao núcleo político
do Estado Social previsto na Constituição de 1988, donde é possível afirmar que, na
inércia dos poderes encarregados precipuamente de implementar políticas públicas,
é obrigação constitucional do Judiciário, através da jurisdição constitucional,
propiciar as condições necessárias para a concretização dos direitos sociais
fundamentais. (STRECK, 2003, p. 224).

Da mesma forma, ao criar mecanismos compensatórios, o legislador torna-se capaz de atender a um dos anseios do mundo globalizado neoliberal: auxiliar a função executiva estatal a tornar a gestão de recursos mais eficiente e produzir melhores resultados, com a preservação de proteções sociais.

Note-se, portanto, que nem mesmo a força ideológica desconstrutiva das proteções sociais - o neoliberalismo -, fundamental à tendência de desmantelamento dos aparatos de proteção social, é capaz de negar o potencial avanço na qualidade da produção legislativa, uma vez vencidas as resistências ao postulado da vedação ao retrocesso social e admitidas as exigências de mecanismos compensatórios.

\section{CONCLUSÃO}


O tema em questão não se esgota aqui e possui relevância atual como também deságua em repercussões de ordem coletiva e social. Nas últimas décadas, o arcabouço jurídico estruturante da rede de proteção social trabalhista tem sido alvo constante de reformas, mitigações e desconstruções. Sempre com foco em eventuais entraves à atividade econômica, o alicerce jurídico protetivo garantidor de cidadania e de salvaguarda aos patamares mínimos civilizatórios tem sofrido reduções significativas.

$\mathrm{O}$ atual contexto de pandemia agravou as vulnerabilidades e abriu novos espaços de reforma e desregulamentação visando a retirada de direitos e a precarização das relações laborais.

Tais proteções e garantias, heranças do Estado Social de Direito, encontram sua razão de existir na dignidade da pessoa humana e na busca pela cidadania plena. Possuem, portanto, status constitucional específico e exigência de concretização efetiva. Trata-se de alicerce democrático do qual a sociedade almejada pela Carta Política de 1988 não pode abrir mão, sob pena de construir suas bases futuras em condições indignificantes.

O princípio da vedação ao retrocesso social parece ser a principal força de resistência e proteção aos patamares mínimos existenciais já concretizados na ordem jurídica. Trata-se de princípio constitucional merecedor de efetividade e verdadeira bússola para a atuação do legislador infraconstitucional.

O postulado da vedação ao retrocesso social, como demonstrado, não implica na paralização da atividade legislativa em matéria de direitos sociais, em especial porque provoca, quando muito, um aperfeiçoamento da ação do legislador e um aprimoramento de sua atividade. Da mesma forma, consagra a ideia de segurança social, em paralelo com a segurança jurídica indispensável ao fortalecimento da busca pela cidadania e pela igualdade substancial.

\section{REFERÊNCIAS}

ADAMI, Eduardo Alfredo. Desenvolvimento da produção da vacina contra uma possível gripe pandêmica. São Paulo, 2017. https://teses.usp.br/teses/disponiveis/87/87131/tde-26022018121443/publico/EduardoAlfredoAdami_Mestrado_I.pdf. Acesso em 02 ago. 2020.

ALEXY, Robert. Teoria dos Direitos Fundamentais. Tradução de Virgílio Afonso da Silva. 2. ed. São Paulo: Malheiros Editores, 2011. 
BARCELLOS, Ana Paula de. A eficácia jurídica dos princípios constitucionais: o princípio da dignidade da pessoa humana. Rio de Janeiro: Renovar, 2002.

BARROSO, Luiz Roberto. Curso de direito constitucional contemporâneo: os conceitos fundamentais e a construção do novo modelo. 8. ed. São Paulo: Saraiva Educação, 2019.

BRANCO, Paulo Gustavo Gonet; COELHO, Inocêncio Mártires; MENDES, Gilmar Ferreira. Curso de direito constitucional. 5. ed. São Paulo: Saraiva, 2010.

BRASIL. Consolidação das leis do trabalho e constituição federal. 52. ed. Saraiva, 2019.

CANOTILHO, José Joaquim Gomes. Direito constitucional e teoria da constituição. 7. ed. Coimbra: Almedina, 2003.

2015 .

. O direito constitucional como ciência de direção. 2. ed. São Paulo: Saraiva,

CALVET, Otavio. Legislação Internacional do Trabalho. Rio de Janeiro: Labor Editora, 2012.

DELGADO, Mauricio Godinho. Curso de direito do trabalho. 15. ed. São Paulo: LTr, 2016.

DERBLI, Felipe. O princípio da proibição de retrocesso social na constituição de 1988.

Rio de Janeiro: Renovar, 2007.

FEITO, Lydia. Vulnerabilidad. Anales del sistema sanitario de Navarra. Madrid, v. 30, 3. ed. p. 7-22, 2017.

FERRAJOLI, Luigi, Derechos y Garantías. La ley del más débil. 4. ed. Madrid: Editorial Trotta, 2004.

GONÇALVES, Cláudia Maria da Costa. Direitos fundamentais sociais: releitura de uma constituição dirigente. Curitiba: Juruá, 2006.

HÄBERLE, Peter. Hermenêutica Constitucional. A Sociedade aberta dos interpretes da Constituição. Contribuição para a interpretação pluralista e "procedimental" da constituição. Tradução de Gilmar Ferreira Mendes. Porto Alegre: Sergio Antonio Fabris Editor, 2003.

JOHNS HOPKINS UNIVERSITY \& MEDICINE. Coronavirus Resource Center. Página Inicial. Disponível em: https://coronavirus.jhu.edu/map.html. Acesso em: 12 abr. 2021.

MELLO, Celso Antônio Bandeira de. Eficácia das normas constitucionais e direitos sociais. São Paulo: Malheiros, 2009.

RE, Lucia. Vulnerability, Care and the Constitutional State. Revista de Estudos Constitucionais, Hermenêutica e Teoria do Direito, São Leopoldo, v. 11, 3. ed, p. 313-326, sep-dec. 2019. 
SAMPAIO, José Adércio Leite. Teoria da constituição e dos direitos fundamentais. Belo Horizonte: Del Rey, 2013.

SARLET, Ingo Wolfgang. A eficácia dos direitos fundamentais. 13. ed. Porto Alegre: Livraria do Advogado, 2018.

SILVA, Fernanda Tartuce. Vulnerabilidade como critério legítimo de desequiparação no processo civil. São Paulo, 2011. $\quad$ Disponível em https://teses.usp.br/teses/disponiveis/2/2137/tde-16082012-

143743/publico/Versao_integral_Fernanda_Tartuce_Silva_Tese_USP.pdf Acesso em 01 ago. 2020.

SOUTO MAIOR. Jorge Luiz. O direito do trabalho como instrumento de justiça social. São Paulo: LTr, 2000.

STRECK, Lênio Luiz. Quinze anos de Constituição - análise crítica da jurisdição constitucional e das possibilidades hermenêuticas de concretização dos direitos fundamentais sociais. Revista da Ajuris - Associação dos Juízes do Rio Grande do Sul, Porto Alegre, v. 30, n.92, p. 212-229, dez. 2003.

SUPIOT, Alain. Homo juridicus. Ensaio sobre a função antropológica do Direito. São Paulo: Livraria Martins Fontes Editora, 2007.

TEPEDINO, Gustavo. SCHREIBER, Anderson. Minorias do direito civil brasileiro. Revista Trimestral de Direito Civil, ano 3, v. 10, p. 135-155, abr/jun. 2002.

TORRES, Ricardo Lobo. A cidadania multidimensional na era dos direitos. In: MELLO, Celso de Albuquerque et al (Coords.). Teoria dos direitos fundamentais. 2. ed. Rio de Janeiro: Renovar, 2001. 